\title{
Poemas de La muerte no es todavía una fiesta
}

\author{
Mirtha Luz Pérez Robledo \\ Selección y nota preliminar \\ de Rafael Mondragón
}

Instituto de Investigaciones Filológicas

Universidad Nacional Autónoma de México

mondragon.rafael@gmail.com

Resumen: $\quad$ Selección del libro de poemas La muerte no es todavía una fiesta de Mirtha Luz Pérez Robledo, dedicado a la memoria de la promotora cultural y defensora de los derechos humanos Nadia Vera. La nota preliminar propone algunas líneas de apreciación de dicho libro y recupera la asociación entre poesía y curación propuesta por la autora.

Palabras clave: Mirtha Luz Pérez Robledo, La muerte no es todavía una fiesta, Nadia Vera.

Abstract: $\quad$ Selection from Mirtha Luz Pérez Robledo's book La muerte no es todavía una fiesta, whose poems were written in memoriam of the cultural promotor and Human Rights defensor Nadia Vera. The preliminary note proposes some insights for the appreciation of the book and recovers the association between poetry and healing proposed by Robledo.

Keywords: $\quad$ Mirtha Luz Pérez Robledo, La muerte no es todavía una fiesta, Nadia Vera.

Recibido: $\quad 20$ de noviembre de 2018

Aceptado: $\quad 25$ de noviembre de 2018

\section{Nota preliminar}

La muerte no es todavía una fiesta forma parte de esa otra historia de la poesía mexicana integrada por los libros de autor. Libros que no tienen ISBN ni circulan comercialmente en librerías, pero que son compartidos con fervor en espacios comunitarios, bibliotecas populares, círculos de lectura y otros espacios de creación y reflexión. Se trata de un libro pequeño, impreso de 
forma artesanal y encuadernado a mano en un cartón forrado de papel algodonado que produce al tacto una sensación de ternura y calidez: una forma material que interpela y convoca a construir una comunidad de lectores que no pasa por la economía del mercado, sino por la del don.

Como dijo su autora en un texto que reproducimos abajo, este es "el libro del amor": una obra de arte hecha para celebrar la vida de Nadia Vera, hija de Mirtha, extraordinaria defensora de los derechos humanos y gestora cultural que fue asesinada el 31 de julio de 2015 en un departamento de la Colonia Narvarte junto a su amigo, el reportero gráfico Rubén Espinosa, y tres mujeres más. ${ }^{1}$ Hay tanta impunidad en este caso (y en tantos otros de este país), que es difícil comenzar a explicar quién es Nadia sin hablar de su asesinato. Pero empezar así es cometer una injusticia. El trabajo de Nadia como defensora de derechos humanos y gestora cultural es extraordinario por su capacidad de tejer vínculos y construir espacios de encuentro entre comunidades usualmente alejadas entre sí. Esos espacios tuvieron siempre la forma de la celebración, y algo de esa forma aparece también en este libro.

Se trata de la celebración de un misterio que está inscrito en el lema de la portada del libro con palabras que reescriben las del Cantar de los cantares: si allí se dice "guárdame en tu corazón como un sello, porque fuerte es el amor como la muerte", el lema en la portada del libro dice "más allá de la muerte el amor". No "más fuerte", pero sí "más allá”: el libro construye un espacio para reunirnos y celebrar la vida de Nadia, incluso si celebrar pasa también por habitar el llanto y las cosas que no comprendemos.

El sello que hermana a los reunidos se llama Nadia. Ella está impresa en todas las personas reunidas en torno de Mirtha y sus hijos, que se reúnen

1 Para la comunidad conformada por los periodistas y defensores de derechos humanos, el asesinato de Nadia y Rubén es uno de los más dolorosos de la historia reciente de México. Ambos acababan de dejar Veracruz, el estado en el que residían, tras haber recibido múltiples amenazas de muerte. En una entrevista concedida a Rompeviento en noviembre de 2014, Nadia había señalado a Javier Duarte, entonces gobernador de Veracruz, como responsable de cualquier posible atentado contra ella (véase $<$ https://youtu.be/PbqwA-O-iFs>). El 21 de junio de 2017, la Comisión de Derechos Humanos de la Ciudad de México emitió la recomendación 4/2017 en donde denunciaba la omisión por parte del Estado mexicano en el momento de investigar el multihomicidio de la Colonia Narvarte con aplicación de perspectiva de género y debida diligencia. Véase el texto en <https://cdhdf.org.mx/2017/o6/recomendacion-42017/>. Un excelente resumen de las omisiones en la investigación puede consultarse en Centro de Derechos Humanos Fray Bartolomé de Las Casas, "Verdad, memoria y justicia para Nadia, Rubén, Yesenia, Mile y Olivia", boletín del 24 de julio de 2018, <https:// frayba.org.mx/verdad-memoria-y-justicia-para-nadia-ruben-yesenia-mile-y-olivia/>. 
cotidianamente en el Festival Internacional Cuatro x Cuatro, fundado por Nadia en 2008 y dirigido hasta el día de hoy por su hermano Shantí, un festival que reúne a bailarines, defensores de derechos humanos, pensadores e investigadores. Ella también reúne a quienes no la conocimos personalmente, pero que de todas maneras fuimos buscados para encontrarnos con esa comunidad. Es mi caso, pues yo vivía a unas cuadras del departamento en donde fueron encontrados Nadia y Rubén: recuerdo haber ido al día siguiente de leer la noticia, junto a muchos desconocidos que llevaban poesía, flores y dibujos para poner en la calle. Ya no sé si la verdad ocurrió así, pero también recuerdo lluvia y canciones.

La muerte no es todavía una fiesta habla de cómo vivir con ese sello que duele, y por eso también me interesa. Ofrece una respuesta a la pregunta de cómo se puede hacer para transitar por el dolor. Construye un saber de la fragilidad. En sus páginas, la poesía adquiere una cualidad de invocación que la hermana con la magia. Leer y escribir esos poemas se vuelve una forma de estar con Nadia y de hacer que resucite. La autora es iniciada por su hija en ese saber de la fragilidad: como dice el estribillo de uno de los poemas más hermosos del libro, "mi corazón es un cántaro roto / tú me mantienes resistiendo" (Pérez 2018). ${ }^{2}$

Algunos de los poemas reconstruyen un mito: Perséfone es raptada por la muerte, que aquí se mantiene impune. La voz poética encarna la figura de Demeter. Canta la promesa del regreso de la hija, que es la llegada de una primavera que hará regenerar el mundo. Escribir es sembrar: ese acto, que hace florecer la tierra, dota a la poesía de una dimensión curativa. En otros poemas del libro todos nos convertimos en naturaleza, de tal manera que la primavera también significa la curación de los lectores allí reunidos.

Después de tantos años, por fin en México se está abriendo un tiempo para la memoria. El evangelio de la justicia transicional denunciado en varios textos de Alejandro Castillejo se instalará en nuestro país, con todo y su aparato conceptual y jurídico, y sus instituciones internacionales: maneras de definir a la violencia, la víctima y el victimario; maneras de pensar la memoria y el olvido, tramitar la justicia y abordar el perdón. Es el momento de defender

2 Mirtha Luz Pérez Robledo, "Verso vertical (viaje a Xibalbá)", en La muerte no es todavía una fiesta, San Cristóbal de Las Casas, Segunda Vuelta, 2018, [s. p.]. Una presentación general de la obra poética de la autora puede leerse en Federico Corral Vallejo, Frágilluzciérnaga: periplo retórico en la poética de Mirtha Luz Pérez Robledo, México, CEID, 2009. 
cuál es la justicia que necesitamos. En ese camino, los poemas de este libro también ofrecen una posibilidad para pensar otra justicia. Por ello Interpretatio. Revista de Hermenéutica se honra en presentarlos.

\section{De por qué escribí La muerte no es todavía una fiesta ${ }^{3}$ MirTHA LUZ PÉREZ Robledo}

Dice José Alejandro Restrepo en su ensayo Del homicidio como dibujo: "Los archivos se visitan una y otra vez, se movilizan, se reinterpretan y nos reinterpretan a nosotros. Su proceder es idéntico al trabajo del editor o del montajista: acopio, selección, conexiones, interpretación y circulación" (Restrepo 2017). En una analogía, le he llamado archivo a lo que pensamos y repensamos durante el proceso de duelo que - cierta estoy - no termina sino hasta que quien lo padece muere también. No solo no termina, sino que se recicla cada vez que el pensamiento se vuelve repetitivo y aumenta esta angustia cuando, a la violencia sufrida por el ser querido, se aúna la violencia institucional y la indiferencia de las mismas instituciones para con el ciudadano, que queda doblemente violentado y abandonado.

La neurosis y angustia que se queda en el cuerpo y en la mente de quien padece una tragedia de perder a un ser querido revuelve las tripas, pero también la imaginación; moviliza, a la par, la moral y el arte; invita a la transfiguración de la crueldad en espiritualidad, como quería Nietzsche.

En este proceso doliente he ido teniendo conciencia para sentirme acompañada de tantas personas solidarias: sabía que Nadia Vera es mi hija, pero no sabía que era causa y motivo, inspiración de tantas expresiones sociales y artísticas. Esta vez agradezco con infinitud a todos los artistas de danza, música y artes plásticas que han ofrendado su arte a la memoria de Nadia Vera. Con especial atención, a mi amigo y poeta Francisco Zúñiga; a Victoria Sáenz de la Editorial Segunda Vuelta, quienes con tanta generosidad han editado el libro; a Daniel Castillo, solidario artista plástico, ha creado el diseño de la portada del libro. A todos los amigos de la comunidad de artes escénicas,

3 Palabras leídas por la autora en la presentación de La muerte no es todavía una fiesta en el espacio cultural Na Bolom, en San Cristóbal de Las Casas, Chiapas, el 18 de noviembre de 2018, en el marco de la décima edición del Festival Internacional Cuatro x Cuatro. 
quienes nos han brindado su abrazo en el momento más oscuro de nuestras vidas. Muchos de ellos están aquí presentes, solidarios, amorosos, sin importar el género, lo digo así, con estas palabras que no alcanzan a expresar todo lo que una quisiera decir, porque el lenguaje también es arbitrario. Gracias doy con el corazón.

\section{De por qué escribí La muerte no es todavía una fiesta}

Como los mirmidones en torno a la tumba de Patroclo, he dado vueltas y vueltas en torno a la tumba de mi hija; como Aquiles he iniciado lamentaciones, pero al contrario de él no me han dejado poner mis manos sobre el pecho de mi niña, ni puedo iniciar una venganza en contra de aquellos que le han hecho daño porque no sé quiénes son, no sé cómo son sus rostros ni quiero saberlo. Ha habido un funeral, pero no lo recuerdo, sin embargo, sé que la he soñado. Como Aquiles he ofrendado mi cabellera e invocado al viento para que le lleve mis palabras, porque, como dijo su hermano Shantí Vera: "Hermana, te encuentro en el viento". No entregué el cuerpo de mi hija al fuego, ella ha sido semilla y había que entregarla a la Tierra.

Qué solos se quedan los muertos ha escrito Bécquer, pero yo no he querido que se quede sola, voy a estar con ella, a hablarle, a cantarle, a leer los poemas que para ella escribí; son la oración que no aprendí de niña; porque creo en el verso que el poeta José Ángel Valente escribió: Óyeme tú, dondequiera que estés, estás más vivo.

Estos versos que he escrito en La muerte no es todavía una fiesta no son lamento ni lágrima; son hilos para tejer un lienzo que envuelva su cuerpo y lo arrope amorosamente; es el libro del amor. En la medida que ustedes lean los versos, me acompañarán a tejer ese lienzo amoroso.

Escribir, dijo Séneca, es una forma de contribuir a preservar la memoria de los que hemos perdido.

\section{Poemas de La muerte no es todavía una fiesta}

hayan palabras duras como tus dientes como tus cabellos onduladas palabras sean suaves como tus venas sean las palabras rítmicas como tu corazón latiendo 
abiertas palabras amorosas como las aves de tus manos afanosas lucérnulas entre la hierba noctívagas flores se abren en medio de la noche diminutas como el lunar de tu mejilla insecto azul metálico se pose entre los pétalos de una florecilla de la nimia pradera urbana caracol que repta sobre la superficie de una ancha hoja de papel pájaro que picotea al azar las plantas del jardín flor de azahar abriéndose a la luz $* * *$

Resucitar así entre las palabras que se han vuelto flores entre flores que se han vuelto palabras en esta pradera de mi cuaderno rimar pradera con Vera rimar Nadia con fronda varia volverte árbol

flor luz vegetal saberte una mariposa que forma sus alas con los pétalos de una rosa anaranjada rimar remar reír en el mar de flores como un caracol remar en el viento como una pájara silbar tres veces en medio de la hoja para que aparezcas decir un conjuro de tres palabras para la resurrección HASHANASÉ HASHANASÉ Abra palabra

$* * *$

Cuando llueve oigo tu voz me parece oír tu voz tu risa entre la lluvia 
La hierba roja de tu sangre se extendió por las losetas ávidamente y volviose jardín toda la estancia pradera de flores rojas toda la calle el tiempo fue convirtiendo el fresco fulgor de la sangre en vidriada estrella que se desprendió poco a poco y al contacto con el agua se diluía como si la tierra hubiese abierto sus venas y al mismo tiempo las absorbía el sudario de tu cuerpo que lavé con mis lágrimas se arrugó y como un lienzo que un artista ha intervenido variadas formas de una abstracción plástica aparecieron flores brotaron donde el rastro de la sangre se perdió

$* * *$

Dicen que cuando dicten sentencia una calle para tu nombre reparará el daño pero yo quisiera una calle donde tú y yo camináramos juntas en aquel pueblo nuestro camináramos juntas riéndonos platicando con aquellas palabras sólo nuestras que exportábamos a los habitantes de otras ciudades que se ganaban nuestro corazón

Una calle para tu nombre no repararía el daño en este país de sombras tendría que ser una calle donde una mujer pudiera caminar segura tendría que ser una calle donde cualquier persona pudiera caminar de noche sin sentir miedo tendría que ser una calle como un libro un lugar seguro una calle para reparar el daño es inexistente lugar en este país de sombras perdidas

\section{Bibliografía}

PÉRez Robledo, Mirtha Luz (2018). La muerte no es todavía una fiesta. San Cristóbal de Las Casas, Segunda Vuelta. 
Restrepo, José Alejandro (2017). "Del homicidio como dibujo”, Antípoda. Revista de Antropología y Arqueología, núm. 29 (septiembre-diciembre), <https://revistas. uniandes.edu.co/doi/full/10.7440/antipoda29.2017.10>. Visitado el 30 de noviembre de 2018.

\section{Mirtha Luz Pérez Robledo}

Nació en Comalapa, Chiapas. Es maestra normalista de profesión. Su obra literaria ha sido acreedora a los siguientes reconocimientos: segundo lugar en los Juegos Florales de San Marcos (2001), primer lugar en el Premio Estatal de Poesía "Ydalio Huerta Escalante" (2001), Premio Nacional de Cuento "Carmen Báez" (2001), Premio Estatal de Poesía "Armando Duvalier” (2003) y Premio Nacional de Poesía "Ramón Iván Suárez Caamal" (2006). Su obra literaria ha sido recogida en A la diestra del reino (2004), Vacío bajo la luna y el dulce retorno (2008), La danza de la luz (2008) y Música para una infancia difusa (2009).

\section{Rafael Mondragón}

Doctor en Letras por la Universidad Nacional Autónoma de México, en cuya Facultad de Filosofía y Letras es profesor. Miembro del Sistema Nacional de Investigadores (Nivel I). Investigador del Seminario de Hermenéutica del Instituto de Investigaciones Filológicas y colaborador regular en círculos de lectura, talleres de educación popular y experiencias de trabajo cultural comunitario. Coordina el seminario "Una mesa para compartir objetos" que reúne a defensores de derechos humanos, investigadores y creadores dedicados a la sistematización de experiencias de acción cultural que enfrentan la violencia en nuestro país. Es autor del libro Filosofía y narración. Escolio a tres textos del exilio argentino de Francisco Bilbao (1858-1864), y editor de Interpretatio. Revista de Hermenéutica. 